\title{
GREY WOLF OPTIMIZER BASED OPTIMAL PLACEMENT OF MULTIPLE FACTS DEVICES IN THE TRANSMISSION SYSTEM UNDER DYNAMIC LOADING SYSTEM
}

\author{
YUSUF SAMUEL SUNDAY ${ }^{* 1}$, OKORIE PATRICK UBEH ${ }^{1}$, ABUBAKAR ADAMU \\ SAIDU $^{1}$, ALHASSAN FAHAD ${ }^{1}$ \\ ${ }^{1}$ Department of Electrical Engineering, Ahmadu Bello University, Zaria, Nigeria.
}

\begin{abstract}
The application of grey wolf optimization technique for multiple FACTS placement is presented in this paper for the reduction of total system losses and minimization of voltage deviation via optimal placement of Flexible AC Transmission System (FACTS) device. Grey wolf optimization (GWO) technique is inspired by social hierarchy and hunting behaviour of wolves and offers a right balance between exploration and exploitation during the search for global optimal. Series-shunt FACTS device; unified power flow controller (UPFC) is considered as a formidable device that can provides an alternative option for the flexible controllability and improvement of power transfer capability of a transmission lines. The analyses were conducted by increasing the number of UPFC in the network in order to evaluate the optimal number of FACTS devices that would give the least loss under maximum loading and contingency conditions. The efficacy of this proposed technique is demonstrated on 31-bus, $330 \mathrm{kV}$ Nigeria National Grid (NNG) using MATLAB environment. The results show that optimal placement of FACTS device along with optimization technique provides a promising solution to the high power loss and voltage deviation bedevilling Nigeria National Grid.
\end{abstract}

Keywords: grey wolf optimizer, nigeria national grid, transmission line, UPFC, voltage stability

\section{INTRODUCTION}

In recent years, the power system is witnessing an unprecedented and alarming increase in demand for quality and secure electrical energy, due to the population growth, rising standards of living and recursive increase in technological development under contingency and restructured market environment. This increase in demand has not been adequately compensated by sufficient generation and transmission capacities, owing to economic, political and environmental constraints that limit the utility companies from expanding their generation and transmission facilities [1-3]. Therefore, the present-day researchers are focusing more attention on innovative solutions and technologies with improved energy planning and the use of smart technologies to better the system efficiency, stability and security $[4,5]$. In order to achieve the above stated objectives, the need to install a robust and environmental-friendly device in an existing transmission facilities to provide a better voltage and power flow control, system flexibility, improving power carrying capacity and superior power quality of the existing transmission assets is utmost important [6-8]. This has led to the application of power electronics based controlled devices known as Flexible AC Transmission System [2, 8, 9]. This device enhances network stability without changing the network topology $[10,11]$.

\footnotetext{
* Corresponding author, email: yusufssamuel@gmail.com

(C) 2021 Alma Mater Publishing House
} 
FACTS device offers the following benefits to the network where it is connected; lessen congestion in critically networks, lower system losses, enhanced system stability, power (real and reactive) control as well as adaptive to frequent change of voltage-magnitude simultaneously as a result of their flexibility and fast control mechanism etc. [12-15]. The combination of FACTS devices along with optimization technique is the leading method used in modern power systems to efficiently increase system stability [16]. The economic constraints involved in the procuring and installing this device have mandated adequate planning towards optimal size and allocation of this device at an appropriate location, because in order to derive the full advantages of these devices, it greatly depends on the settings and location in the network $[5,17]$.

Over the last decades, diverse innovative solutions and technologies for the attainment of desired energy planning, enhancement of power transfer capability and smart grids via FACTS placement to improve the system efficiency have been presented at different power system levels from generation to the end-users point using linear and nonlinear techniques [18]. In Refs [19-23], the mathematical linear programming Mixed-Integer Non-Linear Programming (MINLP) Method was integrated for optimal size and location of FACTS devices for the reduction of active power loss and voltage magnitude enhancement. However, there are some salient drawbacks of this linear programming (MINLP), which includes premature convergence, coding complexity and difficulty in implementation.

Recently, there have been rapid interests in the nature-inspired algorithm for the optimal allocation of FACTS devices, because optimal FACTS placement problem is considered as a non-convex and combinatorial analysis which can best be solved using robust metaheuristic methods [24-26]. Several metaheuristic techniques have been developed and deployed for optimal allocation of FACTS devices, because they are simple to implement, flexible and efficient approaches. They can solve discreet, non-convex and complex optimization problems. Some of the metaheuristics approaches that have been used for FACTS placement includes Differential Evolution (DE) [2729], Genetic Algorithm [28, 30, 31], Tabu Search [32-34], Simulated Annealing [35, 36], Particle Swarm Optimization [37], Immune Algorithm [38, 39], Ant Bee Colony [40, 41]. In continuation of the previous works, Authors in $[5,6,42]$ developed Deferential Evolution Algorithm to determine the optimal placement of multi-type FACTS devices in order to lessen the overall system cost, mitigate network congestion and power losses reduction. Ageist Spider Monkey Optimization (ASMO) and a fuzzy-logic based procedure was deployed for optimal locations and sizing of TCSC and TCPST for voltage stability margin improvement and power losses reduction in the power sector [43]. A novel technique for optimal placement of UPFC to eliminate network overloading during single-line fault was investigated in $[2,44]$.

The rest of the paper is organized as follows: 31-bus, $330 \mathrm{kV}$ Nigeria National Grid is introduced in Section 2. Section 3, deals with Static modelling of UPFC and mathematical formulation of the multi-objective functions with the aim of minimizing power loss and enhances power transfer capability. Meta-heuristic algorithm, namely GWO is proposed for solving non-convex optimization problem. However, Section 4 focuses on the simulation and analysis of results obtained for 31-bus, $330 \mathrm{kV}$ NNG. Finally, concluding comments and directions for future research are given in Section 5.

\section{THE 31-BUS, 330 KV NIGERIA NATIONAL GRID DESCRIPTION}

The 31-bus, $330 \mathrm{kV}$ comprises of twenty four (24) load buses (PQ), and thirty-seven (37) transmission lines. It is made up of $6,000 \mathrm{~km}$ of $132 \mathrm{kV}$ lines, $5,000 \mathrm{~km}$ of $330 \mathrm{kV}$ lines, $23 \mathrm{~km}$ of $330 / 132 \mathrm{kV}$ sub-stations and $91 \mathrm{~km}$ of $132 / 33 \mathrm{kV}$. The NNG consists of three (3) hydro and six (6) thermal generating stations, with a total installed capacity of 6500MW [45]. Figure 1 shows the single line representation of 31-bus, $330 \mathrm{kV} \mathrm{NNG.} \mathrm{Due} \mathrm{to} \mathrm{the} \mathrm{size}$ and complexity of this network coupled with exponential rise in demand for electricity, the network is facing some challenges such as; thermal limits violation, long transmission lines which results in high power losses, frequent system collapse, aging and obsolete facilities, and poor voltage profile [46]. A technically attractive solution to these challenges is to upgrade electrical transmission systems infrastructure in the form of building a new generating unit, substations and expanding transmission capacity to cater for the rising demand, so as to boost the system reliability, security and stability. However, researches have proven over the years that economic, political, environmental impacts and construction time have made these measures not to be desirable [3]. These glitches have strongly demanded for the optimization and upgrading of the existing network capacity by the effective application of FACTS technology along with optimization technique to provide advanced solutions and costeffective alternative to building new transmission line [47-50]. This paper presents the combination of FACTS device (UPFC) along with GWO optimization technique to solve the numerous challenges facing NNG network. 


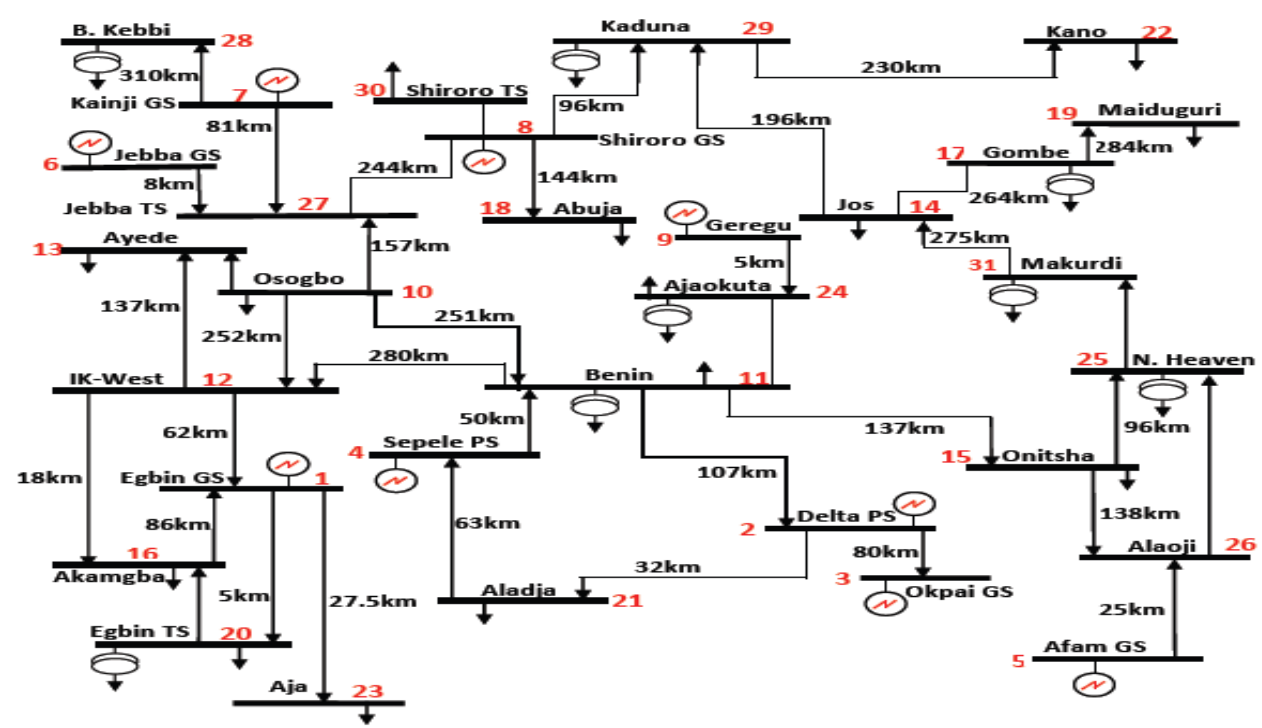

Fig. 1. Single line representation of 31-Bus, $330 \mathrm{kV} \mathrm{NNG} \mathrm{[45].}$

\subsection{Flexible AC transmission system}

FACTS devices over the years have brought to bear, the perceptions that network instability and constraints can be solved successfully and promptly by deferring or eliminating the need for upgrading or building new transmission lines [2, 3]. Amidst the various well known FACTS devices, UPFC is the most commonly used, because of its unique ability to provide independent and/or simultaneous control of the bus voltage magnitude and active and reactive power flow through the transmission line where it is placed $[12,51]$.

\subsubsection{UPFC modelling}

UPFC device is a versatile and adaptable FACTS controller. It provides an excellent adaption to recurrent changes of network operational conditions and enhances the usage of an existing network asset [2]. It is a device which simultaneously combines both shunt compensating and a phase shifting technology. UPFC has an outstanding ability to simultaneously and/or independently control voltage, phase angle shifting, impedance control, active and reactive power flow of a power system [5]. It is modelled as a combination of TCSC (series controller) and SVC (shunt controller) connected in the line/bus through boosting or exciting transformers. This has made UPFC more versatile and widely used than other FACTS devices. Figure 2 shows a schematic representation of UPFC. The detailed mathematical modelling for UPFC direct voltage injection, bus voltage regulation, line impedance compensation and phase angle regulation are presented in $[12,52,53]$.

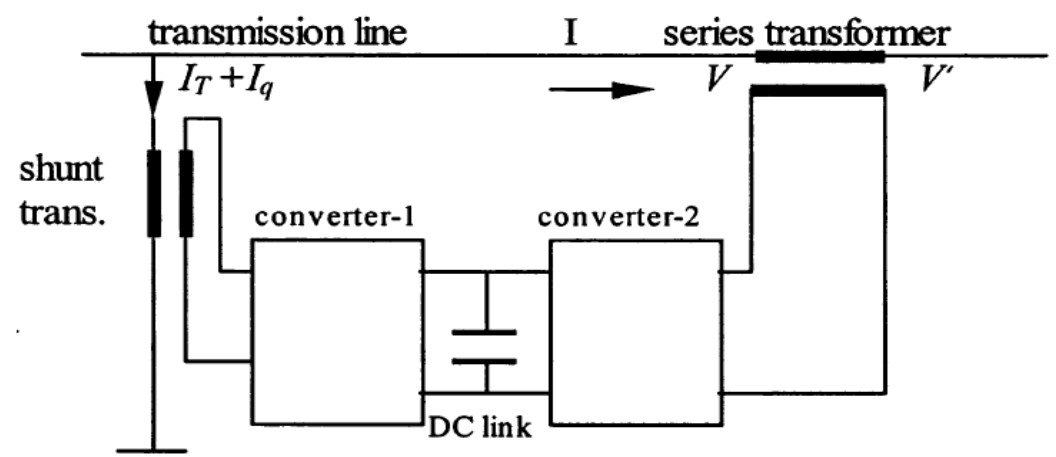

Fig. 2. Schematic representation of UPFC $[12,52]$.

The injected real and reactive power at bus- $i$ with the system loading $(\lambda)$ is obtained using equations (1) and (2):

$$
P_{i}=P_{g i}-P_{d i}^{0}(1+\lambda)=\sum_{j \in N_{b}} P_{i j}
$$




$$
Q_{i}=Q_{g i}-Q_{d i}^{0}(1+\lambda)=\sum_{j \in N_{b}} Q_{i j}
$$

The initial real and reactive power demand is denoted by $P_{d i}^{0}$ and $Q_{d i}^{0}$, while $P_{g i}$ and $Q_{g i}$ represents powers (real and reactive) generation at bus- $i$. In the equations (1) and (2), it is assumed that a uniform loading $(\lambda)$ of power demand at all the load buses have been considered and to be compensated by the slack bus. With this model, sharing of power generated among the generators can efficiently be integrated [12].

\subsection{Overview of grey wolf optimization technique}

Based on the social hierarchy and hunting characteristics of grey wolf (Canis lupus), a metaheuristic algorithm called Grey Wolf Optimizer (GWO) was proposed by Syedali in the year 2014 [54]. This animal is regarded as the apex predator because of their superior hunting behaviour. They live in a pack of average size of 5-10. Wolves are grouped into four categories based on their dominancy order of alpha $(\alpha)$, beta $(\beta)$, delta $(\delta)$, and omega $(\omega)$ [55]. The dominant social hierarchy of grey wolves is shown in Figure 3, the dominancy decreases downwards from alpha (decision maker) to the omega (follower with the least level of hierarchy) search agents. The leaders of the pack are a male and a female known as alphas $(\alpha)$. They are endowed with the ability to manage pack properly by commanding the other lower-level wolves. Alpha takes all decisions regarding place to sleep, hunting activities, waking time etc. The three main hunting phases are; tracking, encircling and attacking towards the prey. Alpha led the hunt while beta and delta wolves play supportive roles. The fittest solution is determined by the alpha due to its best knowledge and social dominance in the pack, while beta and delta offers the second and third best solutions, the other candidate solutions is gamma. GWO algorithm has proven to strike the right balance between exploitation and exploration of the unknown search spaces and yields a favourable result at a very fast rate [54].

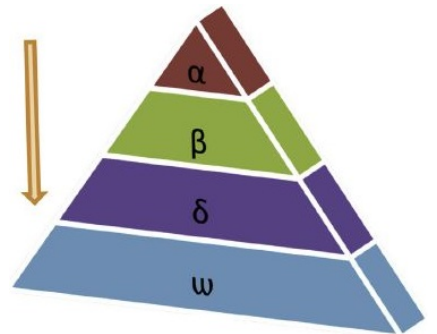

Fig. 3. Dominant social hierarchy of grey wolves [4].

\subsubsection{Mathematical modelling of $G W O$}

This section provides the main steps in the mathematical modelling of GWO:

Social Hierarchy is mathematically modelled by considering alpha as the solution of best fit; beta and delta are taken as the second and third best fits respectively, while omega is considered as other candidate solutions. The GWO algorithm is guided by three wolves namely; alpha, beta and delta while omega is considered as follower with the least hierarchy in the pack.

Encircling prey. The first stage in the hunting characteristics of grey wolf is to circle-shaped the region of the prey; these are modelled mathematically in equations (3) and (4):

$$
\begin{gathered}
\vec{X}=\left|\vec{A} \cdot \vec{W}_{\text {prey }}(t)-\vec{W}(t)\right| \\
\vec{W}(t+1)=\vec{W}_{\text {Prey }}(t)-\vec{S} \cdot \vec{X}
\end{gathered}
$$

Where the current iteration is denoted by $t, \overrightarrow{\mathrm{S}}$ and $\overrightarrow{\mathrm{A}}$ are vector coefficients, the prey position vector is represented by $\overrightarrow{\mathrm{W}}_{\text {prey }}, \overrightarrow{\mathrm{W}}$ indicates the position of the grey wolf. The vectors $\vec{S}$ and $\vec{A}$ are computed by Eq. (5):

$$
\vec{S}=2 \vec{a} \cdot \vec{r}_{1}-\vec{a}, \text { and } \vec{A}=2 \cdot \vec{r}_{2}
$$

$\vec{a}$ are linearly decrease from 2 to $0, r_{1}$ and $r_{2}$ are the random vector between $[0,1]$.

Hunting. Wolves have the capacity to detect the exact position of the prey and encircle it. Alpha being the dominant in the pack lead the hunt and delta and beta sometimes participate in the hunting. In order to develop the 
mathematical modelling of this behaviour; alpha (the fittest candidate solution), beta and delta are assumed to have the best knowledge of the precise (optimum) location of the prey. Hence, the first three best candidate solutions obtained are saved (i.e $\alpha, \beta$ and $\delta$ ) and then the other search agents including the omega $(\omega)$ positions are updated using equations (6) and (7):

$$
\begin{aligned}
& \vec{X}_{\alpha}=\left|\vec{A}_{1} \cdot \vec{W}_{\alpha}-\vec{W}\right|, \quad \vec{X}_{\beta}=\left|\vec{A}_{2} \cdot \vec{W}_{\beta}-\vec{W}\right|, \quad \vec{X}_{\delta}=\left|\vec{A}_{3} \cdot \vec{W}_{\delta}-\vec{W}\right| \\
& \vec{W}_{1}=\vec{W}_{\alpha}-\vec{S}_{1} \cdot\left(\vec{X}_{\alpha}\right), \quad \vec{W}_{2}=\vec{W}_{\beta}-\vec{S}_{2} \cdot\left(\vec{X}_{\beta}\right), \quad \vec{W}_{3}=\vec{W}_{\delta}-\vec{S}_{3} \cdot\left(\vec{X}_{\delta}\right)
\end{aligned}
$$

The search agent exact position is obtained by taken the average sum of equation (7) as follows:

$$
W_{(t+1)}=\frac{\vec{W}_{1}+\vec{W}_{2}+\vec{W}_{3}}{3}
$$

\subsection{Mathematical formulation of the problem}

In this paper, the 31 -bus, $330 \mathrm{kV} \mathrm{NNG}$ is used for these analyses for multi-objective functions and optimal placement of FACTS devices in order to meet the rising power demand by minimizing a predefined objective functions while satisfying power system constraints:

\subsubsection{Minimization of Real Power Loss}

$$
\text { Minimize/maximum } P_{\text {loss }}(x, y)
$$

Subject to:

$$
\begin{aligned}
& h(x, y)=0 \\
& g(x, y) \leq 0
\end{aligned}
$$

Here, the function to be optimized is $P_{\text {loss }}, h$ is the power balance equation, while the network operating constraints is denoted by $g$ which comprises of generator voltages, power outputs and shunt compensation. The vector $x$ represents dependent variables comprising load voltages, generator reactive powers and transmission lines loadings, and $y$ denotes vector of independent variables consist of transformer tap settings, generator voltage and reactive power injections.

$$
\min P_{\text {loss }}=\sum_{k=1}^{N_{l}}\left[G_{k}\left(V_{i}^{2}+V_{j}^{2}-2 V_{i} V_{j} \cos \theta_{i j}\right)\right.
$$

where $P_{\text {loss }}$ represents active power loss, conductance of branch $k$ is denoted by $G_{k}$, the magnitude of voltage at sending and receiving end buses are $V_{i}$ and $V_{j}$, while $\theta_{i j}$ is the phase angle difference bus between $i^{\text {th }}$ and $j^{t h}$.

\subsubsection{Voltage deviation (VD)}

Minimizing voltage deviation of a network improves the voltage profile of the network. This is mathematically expressed in equation (13):

$$
\min (V D)=\min \left(\sum_{k=1}^{N}\left|V_{i}-V_{j}^{r e f}\right|^{2}\right)
$$

where $V_{i}$ is the voltage at bus $i$ and $V_{j}^{r e f}$ is the limit at reference voltage bus $j$.

Constraints. The network is scheduled to function within specific system constraints to ensure a reliable operation. Equality Constraints. The real and reactive power equality constraints are expressed in equations (14) and (15): 


$$
\begin{gathered}
0=P_{G i}-P_{D i}-V_{G i} \sum_{j \in N i}^{N b} V_{j}\left(G_{i j} \cos \theta_{i j}+B_{i j} \sin \theta_{i j}\right), \quad \text { for } i \in N_{b} \\
0=Q_{G i}-Q_{D i}-V_{G i} \sum_{j \in N i}^{N b} V_{j}\left(G_{i j} \sin \theta_{i j}+B_{i j} \cos \theta_{i j}\right), i \in N_{b}
\end{gathered}
$$

where, the total number of buses is signifies by $N_{b}, P_{G i}$ and $P_{D i}$ denote the overall summation of real power generation and demand, $Q_{G i}$ and $Q_{D i}$ are the reactive power generation and demand, $G_{i j}$ and $B_{i j}$ signify conductance and susceptance between buses $i^{\text {th }}$ and $j^{\text {th }}$ respectively.

Operational Inequality Constraints. The generator and network limits are expressed in terms of lower and upper limits as given by equation (16):

$$
\left.\begin{array}{ll}
V_{G i}^{\min } \leq V_{G i} \leq V_{G i}^{\max } & i \in N_{g} \\
Q_{\text {geni }}^{\min } \leq Q_{\text {geni }} \leq Q_{\text {geni }}^{\max } & i \in N_{g} \\
T_{i}^{\min } \leq T_{i} \leq T_{i}^{\max } & i \in N_{T} \\
P_{\text {geni }}^{\min } \leq P_{\text {geni }} \leq P_{\text {geni }}^{\max } & i \in N_{g}
\end{array}\right]
$$

Constraints associated with FACTS devices. The reactive power limit of the UPFC placed in buses is given in equations (17) and (18):

$$
\begin{gathered}
-0.7 X_{L}(\text { capacitive }) \leq X_{T C S C} \leq 0.2 X_{L}(\text { inductive }) \\
-200 M V A R \leq Q_{S V C} \leq 200 M V A R
\end{gathered}
$$

Here $X_{L}$ is the reactance (p.u); reactance connected in series via boosting transformer with the line is denoted by $X_{T C S C} \cdot Q_{S V C}$ represents reactive power injected in MVar at the bus where SVC is connected.

\section{RESULTS AND DISCUSSION}

This section presents three scenarios: maximum loadability limit without contingency, maximum loadability limit with contingency and loadability limit with single line (N-1) outage conditions on 31-bus, $330 \mathrm{kV}$ Nigeria National Grid. The analyses were conducted by increasing the number of UPFCs in the network in order to evaluate the optimal number of FACTS devices that would give the least loss under the three scenarios. All simulations were computed and analysed in MATLAB R2017b software using Intel(R) Pentium (R) CPU 2020M with Dual Core processor speed of $2.40 \mathrm{GHz}$. The maximum loading of a bus occurred at a point where Newton-Raphson power flow has no value (diverged).

\subsection{Maximum loadability limit without contingency}

To determine the performance and optimal number of FACTS devices that can result in the lowest power loss in the network, GWO algorithm was run on the network under $32.65 \%$ loadability. The initial power loss from power flow analysis before the optimal placement of FACTS devices was found to be $124.9133 \mathrm{MW}$. Table 1 shows the number of UPFC installed, location of UPFC, percentage loadability and total power loss. It is observed that at maximum loading without FACTS placement, lines 7-28 and 12-13 have the highest power losses of $12.73 \mathrm{MW}$ and $8.89 \mathrm{MW}$ respectively due to the large distance from the generating unit and obsolete network facilities. The network was first analysed with single UPFC of -111.50 MVar rating at bus 28 and subsequently increased the UPFC to the optimal number of the device that resulted in the least network loss. With a single UPFC, the initial uncompensated network loss of $124.5133 \mathrm{MW}$ reduces to $121.8912 \mathrm{MW}$. Likewise, after placing the second UPFC of -48.90 MVar rating at bus 19 , the power loss reduces to $120.1055 \mathrm{MW}$, similarly with the third UPFC device (80.23 MVar) optimally placed at bus 9 , the network loss reduces significantly to $118.1018 \mathrm{MW}$. Also after optimal placement of the fourth and fifth UPFCs with ratings -90.08 MVar and 71.52 MVar at buses 22 and 11, the power loss reduces to $117.9805 \mathrm{MW}$ and $117.9100 \mathrm{MW}$ respectively. It is evident that four UPFCs are the optimal and ideal FACTS device that resulted in the least power loss. It can also be inferred from the Table 1, that with additions of more UPFCs strategically located in the network using GWO, the loss reduces progressively, until when the fifth UPFC devices which does not have much significant impact on the network. It shows that the network have 
been saturated with UPFC injections and any further increase in the number of UPFCs placement will amount to little or no improvement on the overall improvement of the network. Based on the Table 1, it can be concluded that placing four UPFCs devices on the 31 -bus, $330 \mathrm{kV} \mathrm{NNG}$ is the optimal FACTS devices for the network.

Table 1. Simulation results of 31-bus, $330 \mathrm{kV}$ NNG at maximum loading.

\begin{tabular}{|l|c|c|c|}
\hline No. of UPFC installed & Location & Percentage Loadability & Total Power Loss (MW) \\
\hline Nil & - & 32.65 & 124.5133 \\
\hline 1 & 28 & 32.65 & 121.8912 \\
\hline 2 & $28 \& 19$ & 32.65 & 120.1055 \\
\hline 3 & $9,28 \& 19$ & 32.65 & 118.1018 \\
\hline 4 & $28,19,22 \& 9$ & 32.65 & 117.9805 \\
\hline 5 & $28,9,19,11 \& 22$ & 32.65 & 117.9100 \\
\hline
\end{tabular}

Figure 4 shows a voltage profile result of a multiple FACTS devices installation in a network under maximum loading condition with and without UPFC device. It can be observed from the analysis that the lower and upper tolerable voltage limits of $0.95 \mathrm{pu}(313.5 \mathrm{kV})$ and $1.05 \mathrm{pu}(346.5 \mathrm{kV})$ which is the $\pm 5 \%$ limit were violated at bus 28. The minimum voltage occurred at bus 28 with $0.9376 \mathrm{p}$.u, with optimal allocation of a single UPFC the voltage magnitude increased to 0.9620 and also increases progressively with the increase in the number of UPFCs installed.

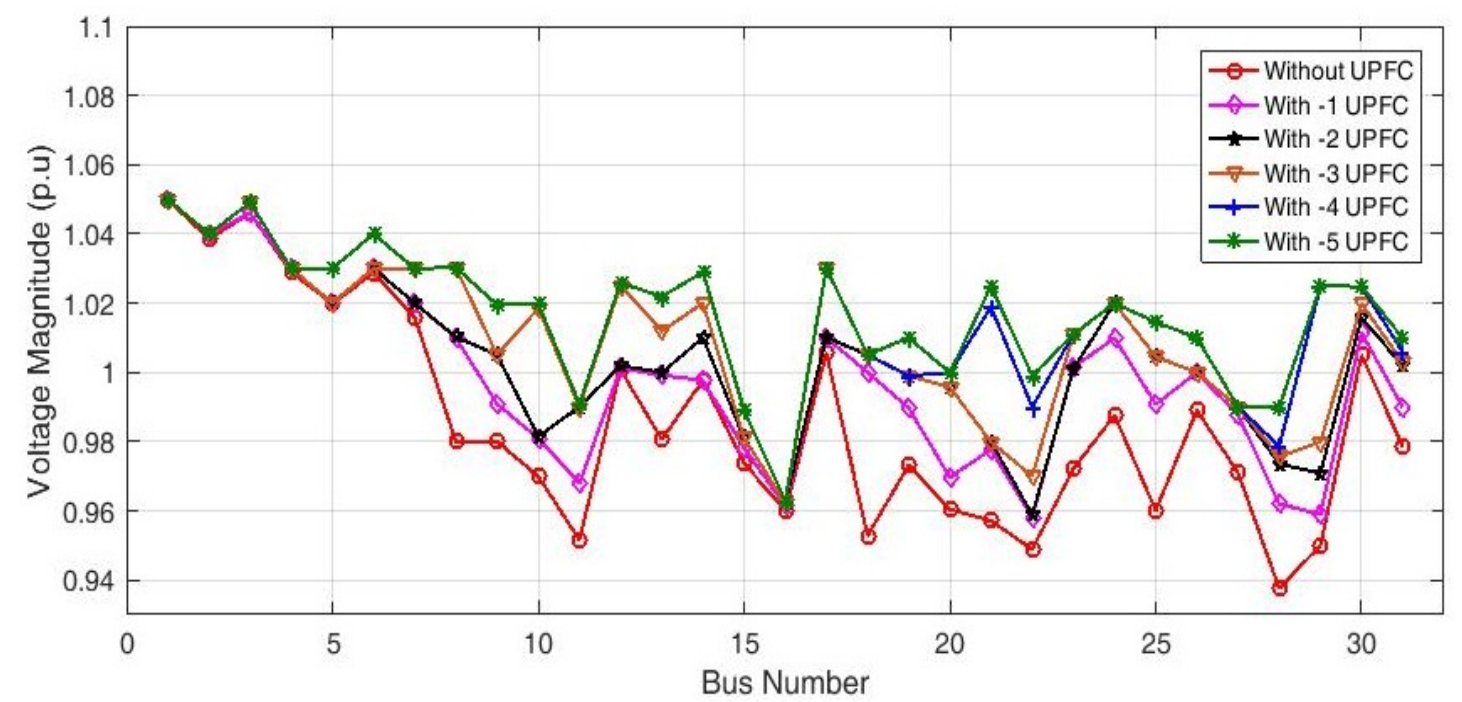

Fig. 4. Voltage profile of 31-Bus, $330 \mathrm{kV} \mathrm{NNG}$ with and without FACTS devices.

\subsection{Loadability Limit with Generator Outage}

Optimal allocation of single and multiple UPFCs is implemented on 31-Bus, $330 \mathrm{kV} \mathrm{NNG}$ under loadability limit with generator outage. This analysis was conducted by varying the number of UPFCs to be integrated in the network, so as to evaluate the optimal number of FACTS devices that will yield the least power loss. The $22^{\text {nd }}$ line which is one of the most sensitive buses is increased to reach a point of bifurcation (a point of voltage collapse) at $28.75 \%$, and bus-5 (generator bus) is made out of service. High severity is witnessed immediately the outage of generator at bus- 5 occurred. Table 2 shows the results obtained with and without FACTS devices placement under loadability limit condition with contingency (generator outage). It is observed that more power losses were noticed in lines 10-11, 7-28, 14-31 and 12-13 being lines that are connected nearer to the critical line (outage Bus-5). An initial uncompensated power loss of 161.6701 MW is obtained in the network. When a single UPFC of -67 MVar rating was installed optimally using GWO in the network, the power losses reduces from the initial value of 161.6701 MW to 159.3270 MW. It is observed that with second, third, fourth and fifth UPFCs of -66.78 MVar, 59.48 MVar, -75.92 MVar, -110.87 MVar ratings optimally placed on the network, the losses reduce to 156.2546 MW, 154.5698 MW, 153.0000 MW and 152.9989 MW respectively. This shows the ability of UPFC at reducing losses on the lines, enhanced transmission capacity and deferring or eliminating for transmission line upgrading. 
Table 2. Maximum Loading and Location of UPFC using GWO with and without UPFC.

\begin{tabular}{|l|c|c|c|}
\hline No. of UPFC installed & Location & Percentage Loadability & Total Power Loss (MW) \\
\hline Nil & - & 28.75 & 161.6701 \\
\hline 1 & 23 & 28.75 & 159.3270 \\
\hline 2 & $28 \& 20$ & 28.75 & 156.2546 \\
\hline 3 & $9,20 \& 28$ & 28.75 & 154.5698 \\
\hline 4 & $28,16,9 \& 22$ & 28.75 & 153.0000 \\
\hline 5 & $22,30,16,28 \& 9$ & 28.75 & 152.9989 \\
\hline
\end{tabular}

The voltage magnitude variation under loadability limit and generator outage is shown in Figure 5. It is observed that, bus-5 (generator) outage has severe effects on the overall magnitude of the voltage; this is as result of the absence of reactive power generation that should support the network from the generator bus. It is also identified that, the voltage magnitude at buses 11, 18,22 and 28 decreases as a result of the lack of generation of the generator (bus-5). But with the installation of multiple UPFCs, a significant voltage improvement is realized on the entire network, especially at Bus19, because it is the receiving end bus where the UPFC is located.

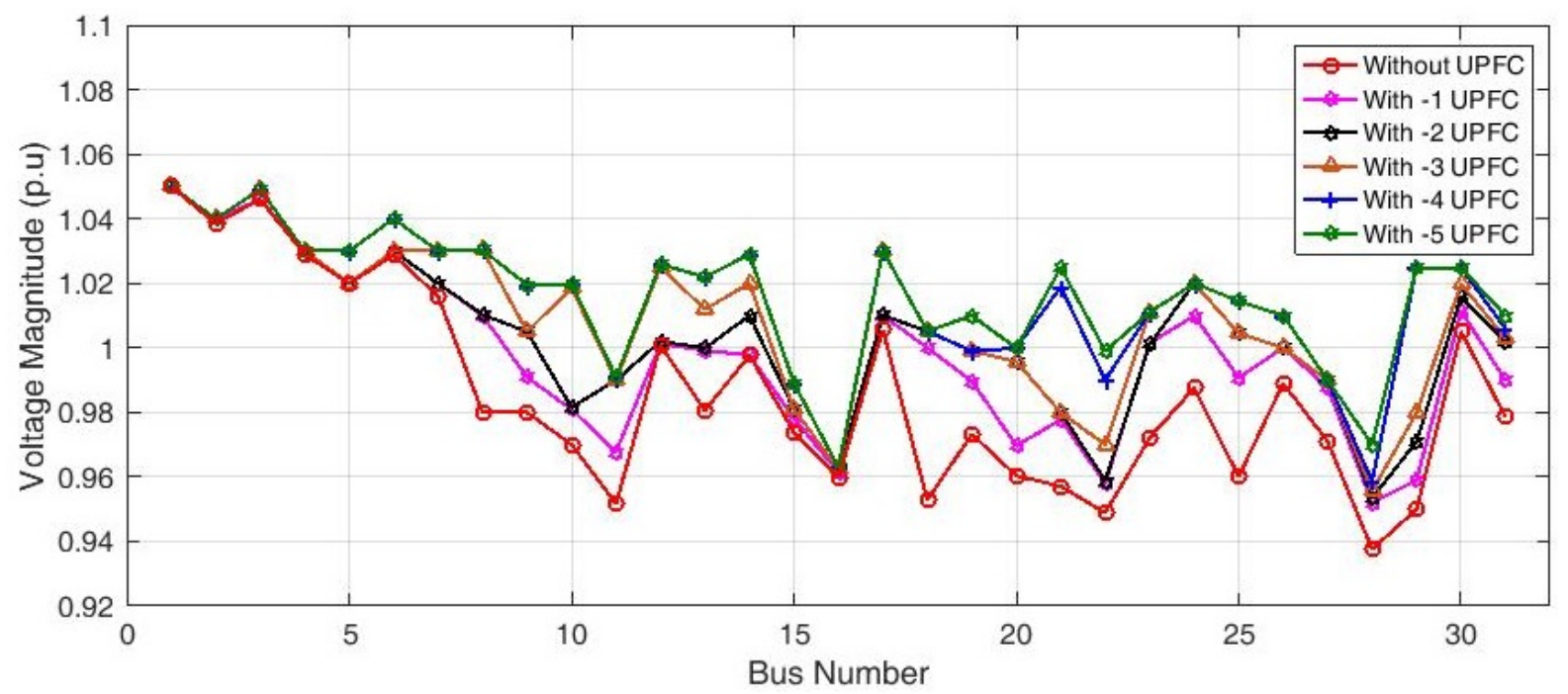

Fig. 5. Voltage profile under generator outage condition.

\subsection{Loadability with Single (N-1) line outage}

Table 3 shows the performance of GWO during a heavy real power loading with single line outage. Table 3 reveals the number of UPFC installed, location of the UPFC, percentage loadability and total power loss. The $28^{\text {th }}$ line which is a critical line is made out of service and Bus 15 real power is raised to a maximum loading of $35.80 \%$. The optimal location and sizing of multiple UPFCs devices was determined based on the GWO algorithm by taking into consideration all contingencies for transmission line capacity improvement and to maintain voltage stability. Table 3 shows the performance of GWO during a heavy real power loading with single line outage. The power flow result revealed that, the outage of bus 15 , increases the losses at line $7-28$, from the initial base case with successive cascading-effects on lines 10-11, 11-15 and 22-29 as a result of their nearer connections to the critical lines (outage line). The initial uncompensated power loss of $142.8091 \mathrm{MW}$ is obtained in the network. The presence of a single UPFC with installed capacity of $-56.39 \mathrm{MVar}$ in the network using GWO, the power loss decreases from initial value of 142.8091 MW to 140.6822 MW. It can also be observed from Table 3, that with second, third, fourth and fifth UPFCs of -95.39 MVar, -70.67 MVar, -108.20 MVar, -73.44 MVar ratings optimally placed on the network, the losses reduce progressively to $141.1260 \mathrm{MW}, 139.4381 \mathrm{MW}, 138.1525 \mathrm{MW}$ and 138.1299 MW respectively for the various optimal multiple UPFCs placements. The significant improvement witnessed on the overall network has further demonstrated the capability of UPFC device at controlling voltage magnitude of a bus and power flow in a line where it is installed. 
Table 3. Simulation results for 31-bus, $330 \mathrm{kV}$ NNG under single line outage.

\begin{tabular}{|l|c|c|c|}
\hline No. of UPFC installed & Location & Percentage Loadability & Total Power Loss (MW) \\
\hline Nil & - & 35.80 & 142.8091 \\
\hline 1 & 28 & 35.80 & 140.6822 \\
\hline 2 & $28 \& 31$ & 35.80 & 141.1260 \\
\hline 3 & $11,28 \& 31$ & 35.80 & 139.4381 \\
\hline 4 & $28,31,11 \& 25$ & 35.80 & 138.1525 \\
\hline 5 & $28,9,31,11 \& 25$ & 35.80 & 138.1299 \\
\hline
\end{tabular}

In order to analyse the steady-state stability condition of the network under a heavy loading real power in Bus-15 and a single line outage, bus 15 is loaded to a maximum load level of $35.80 \%$ and $28^{\text {th }}$ line is made out of service to create contingency. Figure 6 represents voltage profile under heavy real power loading at Bus 15 with single line outage. At bus 28 (0.9399), the peak voltage dip occurred due to the contingency in the network and nearer connection to the line that was made out of service. But with an optimal installation of multiple UPFC devices, the voltage at the buses are augmented and normalized to the tolerable limit.

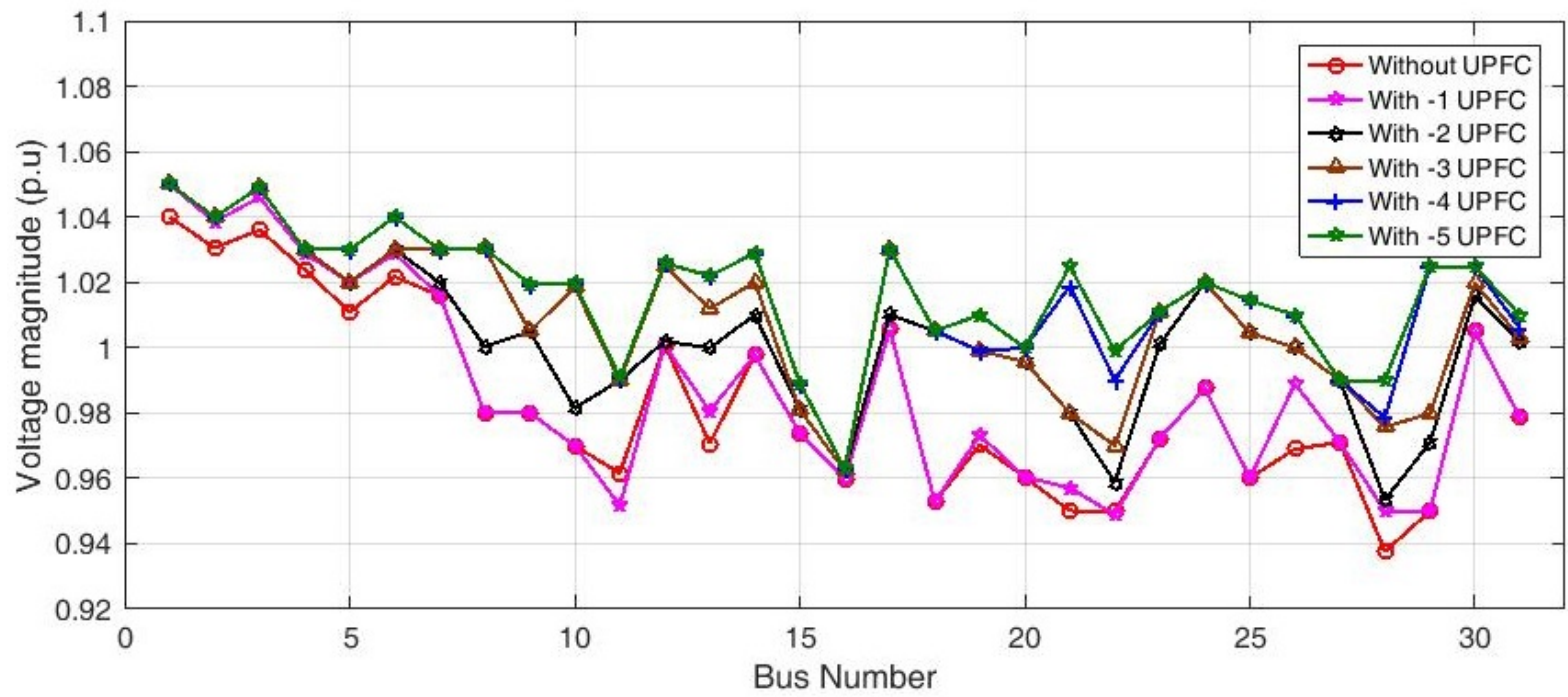

Fig. 6. Voltage profile of 31-bus, $330 \mathrm{kV} \mathrm{NNG} \mathrm{during} \mathrm{single} \mathrm{line} \mathrm{outage.}$

\section{CONCLUSION}

This paper proposes nature-inspired metaheuristic GWO technique for optimal allocation and sizing of multiple UPFCs on 31-bus, $330 \mathrm{kV} \mathrm{NNG}$ for power loss minimization and voltage deviation reduction. The analyses were conducted by increasing the number of UPFC in the network in order to evaluate the optimal number of FACTS devices that would give the least loss under different load variations and contingency for a voltage range of 0.95 p.u. to 1.05 p.u. The results show that using multiple FACTS devices at optimal locations in the network can yields a significant reduction in power loss, loadability enhancement and minimization of voltage deviation while satisfying the network equality and inequality constraints. It is also evident that more power can be wheeled and delivered to meet the ever-growing demand over existing transmission assets during both contingency and load growth conditions without compromising the voltage stability by using the proposed method in this paper. This work can further be extended by using the combination of series and shunt FACTS devices like GUPFC and IPFC that can handle multiple lines simultaneously. Also, cost of installing FACTS devices can also be performed along with this approach.

\section{REFERENCES}

[1] El-Araby, E., Yorino, N., Sasaki, H., A comprehensive approach for FACTS devices optimal allocation to mitigate voltage collapse, IEEE/PES Transmission and Distribution Conference and Exhibition, Yokohama, Japan, vol. 1, 2002, p. 62-67. 
[2] Yusuf, S.S., Boyi, J., Ubeh, O.P., Saidu, A.A., Onimisi, M.I., Transmission line capacity enhancement with unified power flow controller considering loadability analysis, ELEKTRIKA - Journal of electrical engineering, vol. 18 , no. 3,2019 , p. 8-12.

[3] Paserba, J.J., How FACTS controllers-benefit AC transmission systems, IEEE Power engineering society general meeting, Denver, CO, vol. 2, 2004, p. 1257-1262.

[4] Sultana, U., Khairuddin, A.B., Mokhtar, A.S., Sutana, B., Grey wolf optimizer based placement and sizing of multiple distributed generation in the distribution system, Energy, vol. 111, 2016, p. 525-536.

[5] Balamurugan, K., Muthukumar, K., Differential evolution algorithm for contingency analysis-based optimal location of FACTS controllers in deregulated electricity market, Soft computing, vol. 23, no. 1, 2019, p. 163-179.

[6] Agrawal, R., Bharadwaj, S., Kothari, D., Population based evolutionary optimization techniques for optimal allocation and sizing of thyristor controlled series capacitor, Journal of electrical systems and information technology, vol. 5, no. 3, 2018, p. 484-501.

[7] Gyugyi, L., Schauder, C.D., Williams, S.L., Rietman, T.R., Torgerson, D.R., Edris, A., The unified power flow controller: A new approach to power transmission control, IEEE Transactions on power delivery, vol. 10, no. 2, 1995, p. 1085-1097.

[8] Hingorani, N.G., Gyugyi, L., Understanding FACTS: Concepts and technology of flexible AC transmission systems, Wiley-IEEE Press, New York, NY, 1998.

[9] Gaur, D., Mathew, L., Optimal placement of FACTS devices using optimization techniques: A review, IOP Conference series: materials science and engineering, vol. 331, 2017, art.no. 012023

[10] Sharma, P.R., Gupta, A., Optimal placement of FACTS devices for voltage stability using line indicators, IEEE fifth power india conference, Murthal, 2012, p. 1-5.

[11] Mahdad, B., Bouktir, T., Srairi, K., Strategy of location and control of FACTS devices for enhancing power quality, MELECON 2006 - 2006 IEEE mediterranean electrotechnical conference, Malaga, 2006, p. 1068-1072.

[12] Verma, K.S., Singh, S.N., Gupta, H.O., Location of unified power flow controller for congestion management, Electric power systems research, vol. 58, no. 2, 2001, p. 89-96.

[13] Baghaee, H., Jannat, M., Vahidi, B., Hosseinnian, S.H, Rastegar, H., Improvement of voltage stability and reduce power system losses by optimal GA-based allocation of multi-type FACTS devices, 11th International conference on optimization of electrical and electronic equipment, Brasov, 2008, p. 209-214.

[14] Chang, C., Genetic based algorithm for power economic dispatch, IET Generation, Transmission distribution, 2007, p. 261-269.

[15] Khan, I., Mallick, M.A., Rafi, M., Mirza, M.S., Optimal placement of FACTS controller scheme for enhancment of power system security in Indian scenario, Journal of electrical systems and information technology, vol. 2, 2015, p. 161-171.

[16] Ranganathan, S., Kalavathi, M.S., Self-adaptive firefly algorithm based multi-objectives for multi-type FACTS placement, IET generation, transmission \& distribution, vol. 10, no. 11, 2016, p. 2576-2584.

[17] Frolov, V., Thakurta, P.G., Backhaus, S., Bialet, J., Chertkov, M., Operations-and Uncertainty-Aware Installation of FACTS devices in a large transmission system, IEEE transactions on control of network systems, vol. 6, no. 3, 2019, p. 961-970.

[18] Ghiasi, M., Technical and economic evaluation of power quality performance using FACTS devices considering renewable micro-grids, renewable energy focus, vol. 29, 2019, p. 49-62.

[19] Etemad, R., Navabi, R., Shayanfar, H.A., Optimal location and setting of TCSC under single line contingency using mixed integer nonlinear programming, 9th International conference on environment and electrical engineering, Prague, 2010, p. 250-253

[20] Sharma, A.K., Optimal number and location of TCSC and loadability enhancement in deregulated electricity markets using MINLP, International journal of emerging electric power systems, vol. 5, no. 1, 2006.

[21] Tiwari, A., Ajjarapu, V., Optimal allocation of dynamic VAR support using mixed integer dynamic optimization, IEEE transactions on power systems, vol. 26, no. 1, 2010, p. 305-314.

[22] Capitanescu, F., Ramos, J.L.M., Panciatici, P., Kirschen, D., Marcolini, A.M., Platbrood, L., Wehenkel, L., State-of-the-art, challenges, and future trends in security constrained optimal power flow, Electric power systems research, vol. 81, no. 8, 2011, p. 1731-1741.

[23] Aminifar, F., Fotuhi-Firuzabad, M., Khodaei, A., Faried, S.O., Optimal placement of Unified Power Flow Controllers (UPFCs) using mixed-integer non-linear programming (MINLP) Method, IEEE power \& energy society general meeting, Calgary, AB, 2009, p. 1-7

[24] Shaheen, H., Rashed, G., Cheng, S., Application and comparison of computational intelligence techniques for optimal location and parameter setting of UPFC, Engineering applications of artificial intelligence, vol. 23, no. 2, 2010, p. 203-216.

[25] Farsangi, S.E., Rashedi, E., Farsangi, M.M., 2nd Conference on swarm intelligence and evolutionary computation (CSIEC), Kerman, 2017, p. 147-151. 
[26] Surendra, U., Parthasarathy, S., Optimal location of series FACTS device using PSO technique to reduce the losses and to enhance power transfer capability in a power system, Emerging Research in Electronics, Computer Science and Technology, 2014, p. 863-875.

[27] Shaheen, H.I., Rashed, G.I., Cheng, S., Optimal location and parameter setting of UPFC for enhancing power system security based on differential evolution algorithm, International Journal of Electrical Power \& Energy Systems, vol. 33, no. 1, 2011, p. 94-105.

[28] Bhattacharyya, B., Gupta, V.K., Fuzzy based evolutionary algorithm for reactive power optimization with FACTS devices, International Journal of Electrical Power \& Energy Systems, vol. 61, 2014, p. 39-47.

[29] Rashed, G.I., Sun, Y., Shaheen, H., Optimal location and parameter setting of TCSC for loss minimization based on differential evolution and genetic algorithm, Physics Procedia, vol. 33, 2012, p. 1864-1878.

[30] Preethi, V., Muralidharan, S., Rajasekar, S., Application of genetic algorithm to power system voltage stability enhancement using facts devices. International conference on recent advancements in electrical, electronics and control engineering, Sivakasi, 2011, p. 333-338

[31] Gitizadeh, M., Allocation of multi-type FACTS devices using multi-objective genetic algorithm approach for power system reinforcement. Electrical Engineering, vol. 92, no. 6, 2010, p. 227-237.

[32] Oshiro, M., Tanaka, K, Uehara, A., Senjyu, T., Miyazato, Y., Yona, A., Funabashi, T., Optimal voltage control in distribution systems with coordination of distribution installations, International Journal of Electrical Power \& Energy Systems, vol. 32, no. 10, 2010, p. 1125-1134.

[33] Ravindra, S., Suresh, C.V., Sivanagaraju, S., Veera, C.V., Power system security enhancement with unified power flow controller under multi-event contingency conditions; Shams Engineering Journal, vol. 8, no. 1, 2017 , p. 9-28.

[34] Csaszar, P., Tirpak, T.M., Nelson, P.C., Optimization of a high-speed placement machine using tabu search algorithms, Annals of Operations Research, vol. 96, no. 4, 2000, p. 125-147.

[35] Gitizadeh, M., A modified simulated annealing approach to congestion alleviation in a power system using FACTS devices, 45th International Universities Power Engineering Conference UPEC2010, Cardiff, Wales, 2010, p. 1-6.

[36] Majumdar, S., Chakraborty, A., Chattopadhyay, P., Active power loss minimization with FACTS devices using SA/PSO techniques, International Conference on Power Systems, Kharagpur, 2009, p. 1-5.

[37] Chansareewittaya, S., Jirapong, P., Power transfer capability enhancement with multitype FACTS controllers using hybrid particle swarm optimization, Electrical Engineering, vol. 97, no. 2, 2015, p. 119-127.

[38] Taher, S.A., Amooshahi, M.K., Optimal placement of UPFC in power systems using immune algorithm, simulation modelling practice and theory, vol. 19, no. 5, 2011, p. 1399-1412.

[39] Taher, S.A., Amooshahi, M.K., New approach for optimal UPFC placement using hybrid immune algorithm in electric power systems, International Journal of Electrical Power \& Energy Systems, vol. 43, no. 1, 2012, p. 899-909.

[40] Fughar, A., Nwohu, M., Optimal location of STATCOM in Nigerian $330 \mathrm{kV}$ network using ant colony optimization meta-heuristic, Global Journal of Research In Engineering, 2014.

[41] Lin, W., Lu, K., Huang, C., Ou, T., Li, Y., Optimal location and capacity of STATCOM for voltage stability enhancement using ACO plus GA, IEEE/ASME International Conference on Advanced Intelligent Mechatronics, Singapore, 2009, p. 1915-1920.

[42] Mustapha, M., Bakare, G., Dynamic analysis of power loss minimization and voltage profile enhancement using UPFC device with differential evolution algorithm, European Journal of Advances in Engineering and Technology, vol. 4 no. 1, 2017, p. 36-43.

[43] Singh, P., Tiwari, R., Sangwan, V., Gupta, A.K., Optimal allocation of thyristor-controlled series capacitor (tcsc) and thyristor-controlled phase-shifting transformer (TCPST), International Conference on Power Electronics \& IoT Applications in Renewable Energy and its Control (PARC), Mathura, Uttar Pradesh, India, 2020, p. 491496.

[44] Saravanan, M., Slochanal, M.R., Venkatesh, P., Abraham, P.S., Application of PSO technique for optimal location of FACTS devices considering system loadability and cost of installation, I International Power Engineering Conference, Singapore, vol. 2, 2005, p. 716-721.

[45] Ogbuefi, U., Madueme, T., A power flow analysis of the Nigerian $330 \mathrm{KV}$ electric power system, IOSR Journal of Electrical and Electronics Engineering (IOSR-JEEE), vol. 10, no. 1, 2015, p. 46-57.

[46] Omorogiuwa, E., Ike, S., Power flow control in the Nigeria $330 \mathrm{kV}$ integrated power network using unified power flow controller (UPFC). International Journal of Engineering Innovation \& Research, vol. 3, no. 6, 2014, p. 723-731.

[47] Raj, S., Bhattacharyya, B., Optimal placement of TCSC and SVC for reactive power planning using Grey wolf optimization algorithm, Swarm and Evolutionary Computation BASE DATA, 2017, p. 1-29. 
[48] Emmanuel, A.O., Ignatius, K.O., Abel, E.A., Enhancement of power system transient stability, a review, IOSR Journal of Electrical and Electronics Engineering (IOSR-JEEE), vol. 12, no. 3, 2017, p. 32-36.

[49] Suganyadevi, M.V., Babulalb, C.K., Estimating of loadability margin of a power system by comparing voltage stability indices, International Conference on Control, Automation, Communication and Energy Conservation, 2009, p. 1-5.

[50] Ratra, S., Tiwari, R., Niazi, K.R., Voltage stability assessment in power systems using line voltage stability index, Computers \& Electrical Engineering, vol. 70, 2018, p. 199-211.

[51] Ravindra, S., Suresh, C.V., Sivanagaraju, S., Reddy, V.C., Power system security enhancement with unified power flow controller under multi-event contingency conditions, Ain Shams Engineering Journal, 2015, p. 1-10.

[52] Zhang, X.P., Rehtanz, C., Pal, B., Flexible AC transmission systems, Modelling and Control, 2012, Heidelberg New York Dordrecht London, Springer.

[53] Kumar, D., Gupta ,V., Jha, R.C., Implementation of FACTS devices for improvement of voltage stability using evolutionary algorithm, IEEE 1st International Conference on Power Electronics, Intelligent Control and Energy Systems (ICPEICES), Delhi, 2016, p. 1-6.

[54] Mirjalili, S., Mohammad, S., Lewis, A., Advances in engineering software grey wolf optimizer, Advances in Engineering Software, vol. 69, 2014, p. 46-61.

[55] Mech, L.D., Alpha status, dominance and division of labor in wolf packs, Can. J. Zool, vol. 77, 1999, p. 11961203. 